mép cắt trên và dưới âm tính, nối ngay thì đầu với GIST đại tràng kích thước nhỏ, giai đoạn tại chỗ trong tình trạng cấp cứu là có thể thực hiện được và đem lại kết quả bước đầu tốt.

\section{TÀI LIÊU THAM KHẢO}

1. Michael T. Mazur, M.D, H. Brent Clark, M.D, Ph.D. Gastric stromal tumors: Reappraisal of histogenesis. The American Journal of Surgical Pathology. 1983; 7(6): 507-519.

2. Quiroz HJ, Willobee BA, Sussman MS, et al. Pediatric gastrointestinal stromal tumors-a review of diagnostic modalities. Transl Gastroenterol Hepatol. 2018; 3: 54

3. Kotb $M$, Abdelaziz M, Beyaly M, Mekawy $M$, Rashwan H, Mashali N. Neonatal Gastrointestinal Stromal Tumor of the Sigmoid Colon: A Case Report and Review of Literature. Fetal and Pediatric Pathology. 2020; 39(2): 172-178.
4. Trịnh Hồng Sơn. GIST trực tràng kích thước lớn. Tuyển Tập Các Bài Viết Thổng Báo Lâm Sàng. Nhà xuất bản Y hoc; 2014.

5. Kaemmer DA, Otto J, Lassay L, Junge $K_{\text {, }}$ Klinge U. The Gist of Literature on Pediatric GIST. J Pediatr Hematol Oncol. 2009; 31(2): 108-112.

6. Benesch M, Wardelmann E, Ferrari A, Brennan B, Verschuur A. Gastrointestinal stromal tumors (GIST) in children and adolescents: A comprehensive review of the current literature: Gastrointestinal Stromal Tumors. Pediatr Blood Cancer. 2009; 53(7):1171-1179.

7. Herzberg M, Beer $M$, Anupindi S, Vollert $K$ Kröncke T. Imaging pediatric gastrointestinal stromal tumor (GIST). Journal of Pediatric Surgery. 2018; 53(9):1862-1870.

8. Falcone ME. Pediatric Gastrointestinal Tumors Journal of Diagnostic Medical Sonography. 28(3): 131-134.

\title{
HIỆU QUẢ BỔ SUNG SỮA NƯớC HANIE KID LÊN TÌNH TRANG DINH DƯỡNG, SỨC KHỎE VÀ KHẢ NĂNG CHẤP NHẬN SẢN PHẨM CỦA HỌC SINH LỚP MộT
}

\begin{abstract}
TÓM TẮT.
Nghiên cứu có đối chứng, ngẫu nhiên cụm nhằm đánh giá hiệu quả bổ sung Sản phẩm dinh dưỡng sữa pha sắn Hanie Kid dạng lỏng lên tình trạng dinh dưỡng, sức khỏe và khả năng chấp nhận sản phẩm đối với học sinh lớp một (6-7 tuổi). Nghiên cứu được hoàn thành tại Thái Bình vào tháng 3/2021 với 55 trẻ nhóm can thiệp bổ sung Sữa nước Hanie Kid 2 lần/ngày trong 2 tháng và 55 trẻ nhóm chứng với chế độ ăn thông thường. Kết quả nghiên cứu cho thây bổ sung Sữa nước Hanie Kid đã có tác động tích cực: cân nặng trung bình tăng $0,57 \mathrm{~kg}(0,93 \pm 0,3 \mathrm{~kg}$ so với $0,36 \pm 0,17 \mathrm{~kg} ; \mathrm{p}<0,01)$; chiêu cao trung bình tăng $0,37 \mathrm{~cm}(0,96 \pm 0,10 \mathrm{~cm}$ so với $0,59 \pm 0,17 \mathrm{~cm}$; $\mathrm{p}<0,05)$; SDD thể nhẹ cân giảm 12,7\%; nguy cơ SDD nhẹ cân giảm $14,5 \%$ có ý nghĩa thống kê $(p<0,05)$. Có xu hướng cải thiện tình trạng nhiễm khuân hô hấp, tiêu chảy, táo bón, biếng ăn, khó ngủ, nhưng số lượng nhỏ, không có ý nghĩa thống kê ( $p>0,05)$.
\end{abstract}

Tư khóa: đa vi chất, sữa bổ sung, trẻ tiểu học, chiều cao, cân nặng.

\footnotetext{
${ }^{1}$ Trường Đại học Y Hà Nội

${ }^{2}$ Trường Đại học Y Dược Thái Binh

${ }^{3}$ Trường Cao đẳng Y tế Hà Tình

${ }^{4}$ Viện Dinh dưỡng Quốc gia

Chịu trách nhiệm chính: Phạm Quốc Hùng

Email: phamquochung@hmu.edu.vn

Ngày nhận bài: 9.4.2021

Ngày phản biên khoa hoc: 21.5.2021

Ngày duyệt bài: 11.6.2021
}

Phạm Quốc Hùng1, Trần Đình Thoan²,
Nguyễn Văn ${ }^{3}$, Trần Thúy $\mathrm{Nga}^{4}$

\section{SUMMARY}

EFFECTS OF HANIE KID MILK SUPPLEMENT ON NUTRITION STATUS, HEALTH, AND PRODUCT ACCEPTABILITY OF GRADE ONE STUDENTS

A cluster randomized and controlled study was conducted to evaluate the supplemental effects of Hanie Kid liquid powdered milk nutrition product on nutritional status, health and product acceptability for first graders (6-7 years old). The study was completed in Thai Binh in March 2021 with 55 infants supplemented with Hanie Kid Liquid Milk 2 times/day for 2 months and 55 control children using regular diet. Research results showed that Hanie Kid liquid milk supplementation had positive effects: average weight increased $0.53 \mathrm{~kg}(0.93 \pm 0.3 \mathrm{~kg}$ vs. $0.36 \pm$ $0.17 \mathrm{~kg} ; \mathrm{p}<0,01)$; average height increased $0.37 \mathrm{~cm}$ $(0.96 \pm 0.10 \mathrm{~cm}$ vs. $0.59 \pm 0.17 \mathrm{~cm} ; \mathrm{p}<0.05)$; underweight decreased $12.7 \%$; risk of malnutrition $14.5 \%$ weight loss with statistically significant $(p<0.05)$. Tendly improve respiratory infections, diarrhea, constipation, anorexia, difficulty sleeping, but but small quantity and not statistically significant ( $p>0.05)$.

Keywords: micronutrients, formula milk, primary school student, height, weight

\section{I. ĐĂT VẤN ĐỀ}

Tình trạng suy dinh dưỡng (SDD) nhẹ cân, thấp còi của trẻ em, đặc biệt là vùng nông thôn Việt Nam còn là vấn đề sức khỏe quốc gia ảnh hưởng đến tầm vóc, chiều cao, trí tuê và sức lao động của người Việt và được ngành y tế và 
Chính phủ đặc biệt quan tâm[1]. Một trong những biện pháp hữu hiệu là sử dụng sữa được bổ sung vi chất dinh dưỡng (VCDD) [2], [3]. Thành phần, hàm lượng, khẩu phần sữa bổ sung cho trẻ em còn là vấn đề tranh luận. "Sản phẩm dinh dưỡng sữa bột pha sẵn Hanie Kid" dạng lỏng (gọi là Sữa nước Hanie Kid) của NutriCare cân đối năng lượng, chất béo, protein, $\mathrm{DHA}$, FOS/Inulin, HMO (2'-FL), Lysin và bổ sung 28 loại vitamin, khoáng chất theo hướng dẫn của WHO [4] hướng tới đối tượng đích là trẻ em lứa tuổi 1-10 tuổi. Nghiên cứu này nhằm đánh giá hiệu quả của sữa nước Hanie Kid đối với tình trạng dinh dưỡng, sức khỏe và khả năng chấp nhận sản phẩm ở trẻ lớp một (6-7 tuổi).

\section{II. ĐỐI TƯỢNG VÀ PHƯƠNG PHÁP NGHIÊN CỨU}

Đối tượng nghiên cứu: trẻ lớp một ở 02 Trường Tiểu học \& Trung học cơ sở thuộc huyên Kiến Xương, tỉnh Thái Bình đáp ứng tiểu chuẩn chấp nhận và loại trừ nghiên cứu. Tiêu chuẩn lựa chọn: trẻ học lớp một; đang theo học tại trường; không mắc các dị tật bẩm sinh, khuyết tật về tâm thần, vận động hoặc trẻ mắc các bệnh mạn tính; được bố mẹ/người giám hộ đồng ý. Tiểu chuẩn loại trừ: đang có bệnh; thừa cân, béo phì (trẻ có WAZ >2 SD, BAZ>1); đang sử dụng các sản phẩm bổ sung dinh dưỡng, đang tham gia một nghiên cứu khác.

Thiêt kế nghiên cứu: Nghiên cứu thử nghiệm can thiệp cộng đồng có đối chứng, ngẫu nhiên cum.

Thời gian: từ tháng 11/2020 đến 3/2021.

Cỡ mấu, chọn mấu: Có 210 trẻ lớp một đã được khám sàng lọc và chọn ra 110 trẻ chia vào 2 nhóm can thiệp và nhóm chứng.

Sữa bổ sung: sản xuất bởi Công ty Cổ phần dinh dưỡng NutriCare có thành phần cho 2 bữ/ngày gồm: năng lượng (360 kcal); chất béo $(17,1 \mathrm{~g})$; protein $(11,5 \mathrm{~g})$; DHA $(23,8 \mathrm{mg})$; FOS/Inulin (1,72g); HMO (2'-FL (12,3mg); Lysin $(860 \mathrm{mg})$ và 14 vitamin: $A$ (1198 IU), D3 (270IU), E (9IU), K1 (8,42mcg), K2 (12,9mcg), C $(33,2 \mathrm{mg}), \quad$ B1 $(490 \mathrm{mcg})$, B2 $(886 \mathrm{mcg})$, B3 (4328mcg), B5 (1072mcg), B6 (358mcg), B7 $(2,92 \mathrm{mcg}), B 9(106 \mathrm{mcg}), B 12(1,18 \mathrm{mcg})$ và 14 khoáng chất trong đó có Canxi (382mg), Kẽm $(4,64 \mathrm{mg})$, Sắt $(2,78 \mathrm{mg})$, Selen $(15,4 \mathrm{mcg})$, Đồng (68mcg), Iốt ( $83,2 \mathrm{mcg})$, Molypden $(3,16 \mathrm{mcg})$.

Phương pháp đánh giá: so sánh chiều cao, cân nặng trung bình, điểm Z-score cao/tuổi, cân nặng/tuổi, BMI/tuổi, tỷ lệ SDD, bệnh tật theo chuẩn WHO 2007 [5].

Phân tích và xữ lý số liệu: Số liệu được nhập bằng phần mềm Excel 2016 và phân tích bằng phần mềm Anthoplus 1.0.4 (WHO), SPSS IBM 20.0.

Đạo đức nghiên cứu: Nghiên cứu đã được Hội đồng khoa học và đạo đức nghiên cứu Trường Đại học $Y$ Dược Thái Bình phê duyệt. Nghiên cứu tuân thủ thực hành lâm sàng tốt.

\section{KẾT QUẢ NGHIÊN CỨU}

Tổng số có 110 trẻ lớp một tham gia can thiệp gồm 55 trẻ nhóm can thiệp và 55 trẻ nhóm chứng.

Bảng 1. Đặc điểm hai nhóm trước khi can thiệp

\begin{tabular}{|c|c|c|c|}
\hline Chỉ số & Nhóm chứng & Nhóm can thiệp & $\mathbf{p}$ \\
\hline Tỷ lệ trẻ nam & $49,1 \%$ & $49,1 \%$ & (a) \\
\hline Tuối (tháng) & $76,84 \pm 0,44$ & $76,84 \pm 0,44$ & $>0,05^{b}$ \\
\hline Cân nằng (kg) & $17,94 \pm 1,63$ & $17,86 \pm 1,37$ & $>0,05^{b}$ \\
\hline Chiều cao $(\mathrm{cm})$ & $112,52 \pm 4,22$ & $112,52 \pm 4.09$ & $>0,05^{b}$ \\
\hline SDD thể nhẹ cân & $10(18,2 \%)$ & $10(18,2 \%)$ & $(\mathrm{a})$ \\
\hline SDD thế thấp còi & $12(21,8 \%)$ & $12(21,8 \%)$ & $\left(a^{a}\right)$ \\
\hline SDD thế gày còm & $5(9,1 \%)$ & $5(9,1 \%)$ & $(a)$ \\
\hline Viêm đường hô hấp cấp & $6(10,9 \%)$ & $5(9,1 \%)$ & $>0,05^{a}$ \\
\hline Tiêu chảy & $3(5,5 \%)$ & $4(7,3 \%)$ & $>0,05^{b}$ \\
\hline Táo bón & $4(7,3 \%)$ & $5(9,1 \%)$ & $>0,05^{b}$ \\
\hline Biếng ăn & $7(12,7 \%)$ & $8(14,5 \%)$ & $>0,05^{b}$ \\
\hline Khó ngủ & $5(9,1 \%)$ & $5(9,1 \%)$ & (a) \\
\hline
\end{tabular}

a) không có sự khác biệt hoăc dữ liệu nhỏ chiều cao, cân nặng, BMI, Z-core cân nặng/tuối, không làm kiểm định; ' ${ }^{\text {) }}$ T-test; c) Fisher's exact chiêu cao/tuổi, BMI/tuổi, tỷ lệ SDD các thể nhẹ - test, Bootstrap 1000 samples.

Trước can thiệp, không có sự khác biệt có ý nghĩa thống kê (YNTK) (p>0,05) giữa nhóm can thiệp và nhóm chứng về các chỉ số giới, tuổi, cân, thấp còi, gầy còm, tỳ lệ các bệnh viêm đường hô hấp, tiêu chảy, táo bón, biếng ăn, khó ngủ. 
Bảng 2. Hiệu quả bổ sung Sữa nước Hanie Kid lên tình trạng dinh dưỡng

\begin{tabular}{|c|c|c|c|c|}
\hline Chỉ số & Thời gian & $\begin{array}{c}\text { Nhóm chứng } \\
(\bar{X} \pm S D)\end{array}$ & $\begin{array}{c}\text { Nhóm }{ }_{\bar{X}} \pm \text { can thiệp } \\
\end{array}$ & $\mathbf{p}$ \\
\hline \multirow{5}{*}{ Cân nặng (kg) } & T0 & $17,94 \pm 1,63$ & $17,86 \pm 1,37$ & $p>0,05^{b}$ \\
\hline & T1 & $18,12 \pm 1,61$ & $18,35 \pm 1,32$ & $p>0,05^{b}$ \\
\hline & T2 & $18,30 \pm 1,58$ & $18,78 \pm 1,30$ & $\mathrm{p}<0,05^{\mathrm{b}}$ \\
\hline & T1-T0 & $0,18 \pm 0,10$ & $0,46 \pm 0,13$ & $\mathrm{p}<0,05^{\mathrm{b}}$ \\
\hline & T2-T0 & $0,36 \pm 0,17$ & $0,93 \pm 0,30$ & $\mathrm{p}<0,01^{b}$ \\
\hline \multirow{5}{*}{ Chiều cao (cm) } & T0 & $112,45 \pm 4,47$ & $112,43 \pm 4,18$ & $p>0,05^{b}$ \\
\hline & T1 & $112,76 \pm 4,47$ & $112,95 \pm 4,18$ & $p>0,05^{b}$ \\
\hline & T2 & $113,05 \pm 4,7$ & $113,39 \pm 4,2$ & $\mathrm{p}>0,05^{b}$ \\
\hline & T1-T0 & $0,30 \pm 0,10$ & $0,52 \pm 0,09$ & $\mathrm{p}>0,05^{\mathrm{b}}$ \\
\hline & T2-T0 & $0,59 \pm 0,17$ & $0,96 \pm 0,10$ & $\mathrm{p}<0,05^{\mathrm{b}}$ \\
\hline \multirow{4}{*}{$\begin{array}{l}\text { SDD thể nhe cân } \\
\text { (WAZ<-2SंD) }\end{array}$} & T0 & $10(18,2 \%)$ & $10(18,2 \%)$ & (a) \\
\hline & T1 & $9(16,4 \%)$ & $5(9,1 \%)$ & $p>0,05^{c}$ \\
\hline & T2 & $10(18,2 \%)$ & $3(5,5 \%)$ & $\mathrm{p}<0,05^{\mathrm{c}}$ \\
\hline & T0-T2 & $0(\%)$ & $7(12,7 \%)$ & $\mathrm{p}<0,05^{\mathrm{c}}$ \\
\hline \multirow{4}{*}{$\begin{array}{l}\text { SDD \& Nguy cơ } \\
\text { SDD thể nhe cân } \\
\text { (WAZ<-1Ś) }\end{array}$} & T0 & $32(58,2 \%)$ & $35(63,6 \%)$ & $\left(a^{a}\right)$ \\
\hline & T1 & $32(58,2 \%)$ & $31(56,4 \%)$ & $p>0,05^{c}$ \\
\hline & T2 & $32(58,2 \%)$ & $27(49,1 \%)$ & $\mathrm{p}<0,05^{\mathrm{c}}$ \\
\hline & T0-T2 & $0(0 \%)$ & $8(14,5 \%)$ & $\mathrm{p}<0,05^{\mathrm{c}}$ \\
\hline
\end{tabular}

a) không có sự khác biệt hoặc dữ liệu nhỏ không làm kiểm định; b) T-test; c) Fisher's exact - test, Bootstrap 1000 samples.

Tại thời điểm trước can thiệp, không có sự khác biệt về cân nặng, chiều cao giữa 2 nhóm $(p>0,05)$. Tại thời điểm $T 1$, nhóm can thiệp có mức tăng cân tốt hơn nhóm chứng $(0,46 \pm 0,13$ $\mathrm{kg}$ so với $0,18 \pm 0,10 \mathrm{~kg}$ ), chênh lệch $0,28 \mathrm{~kg}$, có YNTK $(p<0,05)$. Tại thời điểm T2, nhóm can thiêp có mức tăng cân tốt hơn nhóm chứng $(0,93 \pm 0,30 \mathrm{~kg}$ so với 0,36 $\pm 0,17 \mathrm{~kg})$, chênh

lệch $0,57 \mathrm{~kg}$ có YNTK $(\mathrm{p}<0,01)$; mức tăng chiều cao $(0,96 \pm 0,10 \mathrm{~cm}$ so với $0,59 \pm 0,17 \mathrm{~cm})$, chênh lệch $0,37 \mathrm{~cm}$, có YNTK $(p<0,05)$. Tỷ lệ SDD thể nhẹ cân ở nhóm can thiệp $(5,5 \%)$ thấp hơn so với nhóm chứng $(18,2 \%)$ ở mức có YNTK $(p<0,05)$. Tỷ lệ SDD ở nhóm can thiệp giảm rõ rệt so với nhóm chứng: SDD thể nhẹ cân chênh lệch $12,7 \%$ có YNTK $(p<0,05)$; nguy cơ SDD nhè cân chênh lệch $14,5 \%$ có YNTK $(p<0,05)$. Khổng xuất hiện thừa cân, béo phì.

Bảng 5. Hiệu quả bổ sung Sữa nước Hanie Kid lên tinh trạng sức khỏe

\begin{tabular}{|c|c|c|c|c|c|c|}
\hline \multirow[b]{2}{*}{ Chỉ số } & \multicolumn{2}{|c|}{ Trước can thiệp } & \multicolumn{2}{|c|}{ Sau CT 1 tháng } & \multicolumn{2}{|c|}{ Sau CT 2 tháng } \\
\hline & $\begin{array}{l}\text { Nhóm } \\
\text { chứng }\end{array}$ & $\begin{array}{l}\text { Nhóm can } \\
\text { thiệp }\end{array}$ & $\begin{array}{l}\text { Nhóm } \\
\text { chứng }\end{array}$ & $\begin{array}{c}\text { Nhóm can } \\
\text { thiệp }\end{array}$ & $\begin{array}{l}\text { Nhóm } \\
\text { chứng }\end{array}$ & $\begin{array}{c}\text { Nhóm can } \\
\text { thiệp }\end{array}$ \\
\hline $\mathrm{NKHH}$ & $6(10,9 \%)$ & $5(9,1 \%)$ & $5(9,1 \%)$ & $4(7,3 \%)$ & $5(9,1 \%)$ & $2(3,6 \%)$ \\
\hline Tiêu chảy & $3(5,5 \%)$ & $4(7,3 \%)$ & $5(9,1 \%)$ & $2(3,6 \%)$ & $5(9,1 \%)$ & $1(1,8 \%)$ \\
\hline & & $5(9,1 \%)$ & $3(5,5 \%)$ & $1(1,8 \%)$ & $4(7,3 \%)$ & $1(1,8 \%)$ \\
\hline $\mathrm{Bi}$ & $7(12,7 \%)$ & $8(14,5 \%)$ & $8(14,5 \%)$ & $5(9,1 \%)$ & $8(14,5 \%)$ & $5 \%$ \\
\hline Khó ngủ & $5(9,1 \%)$ & $5(9,1 \%)$ & $5(9,1 \%)$ & $5(9,1 \%)$ & $5(9,1 \%)$ & $4(7,3 \%)$ \\
\hline
\end{tabular}

Trước can thiệp (T0) nhóm can thiệp và nhóm biếng ăn (9,1\% so với 14,5\%). Đến thời điểm T2 chứng có số lượng và tỷ lệ \% nhiễm khuẩn hô hấp (NKHH), tiểu chảy, táo bón, biếng ăn, khó ngủ tương đương nhau hoặc khác biệt rất nhỏ. Sau một tháng can thiệp (T1), nhóm can thiệp đã có cải thiện hơn nhóm chứng về tỷ lệ nhiễm khuẩn hô hấp $(7,3 \%$ so với $9,1 \%)$; tiêu chảy (3,6\% so với $9,1 \%)$; táo bón ( $1,8 \%$ so với $5,5 \%)$;

(sau hai tháng can thiệp), sự khác biệt giữa nhóm can thiệp và nhóm chứng càng nhiều, tỷ lệ nhiễm khuẩn hô hấp $(3,6 \%$ so với $9,1 \%)$; tiểu chảy $(1,8 \%$ so với $9,1 \%)$; táo bón $(1,8 \%$ so với $7,3 \%)$; biếng ăn (5,5\% so với $14,5 \%)$; khó ngủ $(7,3 \%$ so với $9,1 \%)$. Nhưng những sự khác biệt này không có YNTK $(p>0,05)$.

Bảng 3. Tỷ lệ châp nhận sử dụng sản phẩm sữa nước Hanie Kid

\begin{tabular}{|c|c|c|c|c|}
\hline Thời gian & Số ngày uống & Số suất sữa dự kiến & \multicolumn{2}{|c|}{ Lượng sữa uống thực tế nhóm $\mathbf{A}(\mathbf{n}, \mathbf{\%})$} \\
\hline Tháng 1 & 23 & 2530 & 2477 & $97,9 \%$ \\
\hline Tháng 2 & 22 & 2420 & 2373 & $98,1 \%$ \\
\hline Tống & $\mathbf{4 5}$ & $\mathbf{4 9 5 0}$ & $\mathbf{4 8 5 0}$ & $\mathbf{9 8 , 0} \%$ \\
\hline
\end{tabular}


Bảng trên cho thấy số ngày can thiệp tính của T1 là 23 ngày với 2530 suất sữa dự kiến, của T2 là 22 ngày với 2420 suất sữa dự kiến; tổng cộng 45 ngày với 4950 suất sữa nước. Trên thực tế triển khai đã sử dụng 2477 suất sữa $(97,9 \%)$ trong giai đoạn $T 1$ và 2373 suất sữa $(98,1 \%)$ cho giai đoạn T2. Trung bình đã sử dụng $98 \%$ số sữa theo kế hoạch.

Tỷ lệ sử dụng sữa nước Hanie Kid

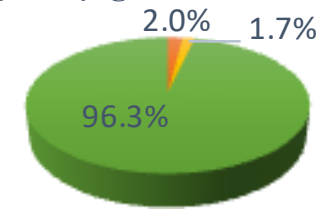

- Không uống Uống thiếu U Uống đủ

\section{Hình 1. Tỷ lệ chấp nhận sử dụng Sữa nước Hannie Kid}

Biểu đồ trên thể hiện kết quả tỷ lệ không uống sữa do các lý do khác nhau như nghỉ học, nghỉ ốm là $2,0 \%$; tỷ lệ uống không hết $1 / 2$ hộp sữa là $1,7 \%$, tỷ lệ uống đủ sữa là $96,3 \%$. Hiện tượng nôn, ói, phản ứng với sữa rất hiếm khi xảy ra.

\section{BÀN LUÂ̂N}

Nhóm can thiệp đã cải thiện mức tăng cân nặng có ý nghĩa thống kê ngay sau 1 tháng sử dụng. Sau 2 tháng cân nặng tăng $0,59 \mathrm{~kg}$ và chiêu cao $0,37 \mathrm{~cm}$, giảm tỷ lệ SDD, nguy cơ SDD và không có thừa cân, đồng thời có xu giảm tỷ lệ viêm đường hô hấp, tiêu chảy, táo bón, biếng ăn, khó ngủ có thể lý giải rằng nhóm đối tượng can thiệp đang thiếu dinh dưỡng trong chế độ ăn uống. Trong khi Hanie Kid đáp ứng kịp thời năng lượng và các chất dinh dưỡng như protein, lipid, carbohydrate hợp lý (khoảng 20-40\% nhu câu của trẻ ở lứa tuổi này), được bổ sung thêm 28 vitamin và chất khoáng quan trọng. Các vi chất này cũng ở hàm lượng đáp ứng được khoảng $50 \%$ nhu câu của trẻ và cân đối với nhau, do đó chúng không ảnh hưởng tới khả năng hấp thu cũng như hoạt động sinh học trong cơ thể của nhau. Trong thành phần của sản phẩm Hanie Kid, các chất dinh dưỡng như lysin, DHA, các axit amin, lipid, 28 loại vitamin, khoáng chất được bổ sung với một hàm lượng phù hợp, hỗ trợ hấp thu, chuyển hóa góp phần vào cải thiện tình trạng SDD và nguy cơ SDD [3]. Đặc biệt Lysin đã được bổ sung cho nhóm can thiệp tới $860 \mathrm{mg} / \mathrm{ngày}$ hỗ trợ cơ thể hấp thu canxi, tạo ra các mạch máu mới, tổng hợp collagen, sản sinh carnitine, giúp hấp thụ tối đa chất dinh dưỡng, sản xuất các enzyme, kháng thể và hormone, giúp cơ thể tăng cường sức đề kháng và tham gia rất nhiều vào các quá trình chuyển hóa, giúp cơ thể phát triển, tăng miễn dịch giúp trẻ ăn ngủ ngon hơn [6]. Vitamin $A$, $D, B$, C, sắt, kẽm, đồng, iot, selen...tham gia chuyển hóa, tăng cường phát triển tế bào tác động đến chiều cao, cân nặng, hệ thống tiêu hóa, miễn dịch. HMO có tác dụng gần như một prebiotic tăng cường lợi khuẩn cho hệ tiêu hoá, tăng cường khả năng miễn dịch. IgG trong thành phần của sữa cho chế độ uống 2 lần/ngày có tác dụng bao phủ niêm mạc ruột làm cho nó không bị các mầm bệnh thâm nhập. Các VCDD có tính chống oxy hoá có vai trò quan trọng trong việc xây dựng, tăng cường, sửa chữa hệ thống miển dịch, tăng sức đề kháng, tăng cường tiêuu hóa làm giảm biếng ăn như kẽm, selen, sắt, đồng, vitamin $A, D, C, E, F O S$ [7]. DHA, Vitamin $D$ và nhiều vi chất khác tham gia vào điều hòa thần kinh làm giảm kích thích khó ngủ. chất xơ hòa tan (FOS/Inulin) chống táo bón rất tốt. Vitamin $C$, vitamin $B 1$, vitamin $B 2 \ldots$ giúp trẻ ăn ngon miệng tăng hấp thu, chuyển hóa, tác động đến tăng khối lượng cơ bắp, xương. Các vi chất khác tham gia vào các quá trình sinh tổng hợp hóc môn và các men, tham gia xây dựng tế bào ví dụ B12, folic tham gia sản xuất hồng cầu, tế bào thần kinh [6]. Việc bổ sung 28 VCDD trong công thức này bổ trợ lẫn nhau có thể cho tác dụng vượt trội so với tăng cường đơn lẻ một hoặc một vài vi chất đã tác động vào hệ thống tiêu hóa, miễn dịch, chuyển hóa, thần kinh thúc đẩy tăng trưởng và tăng cường sức khỏe.

Khả năng chấp nhận sử dụng cao: 96,3\% số trẻ uống đủ khẩu phần sữa (2 bữa/ngày trong 2 tháng). Chương trình bổ sung sữa được gia đình, nhà trường, chính quyền, y tế ủng hộ. Tổng số đã có $98 \%$ lượng sản phẩm đã được sử dụng; Kết quả quan sát và phỏng vấn trong các chuyến giám sát ngẫu nhiên và đánh giá cho thây hầu như toàn bộ phụ huynh và cô giáo luôn ủng hộ. Công thức sữa gồm năng lượng, chất béo, protein, và 28 vitamin và khoáng chất và bố sung thêm DHA, chất xơ hòa tan (FOS/Inulin), HMO (2'-FL), Lysin, được tính theo nhu câu khuyến nghị hàng ngày của Bộ $Y$ tế và Tổ chức $Y$ tế Thế giới và tính toán từ các chuyên gia nhằm hướng tới đối tượng đích là trẻ em lứa tuổi 1-10 tuổi cũng là một yếu tố để các phụ huynh, cô giáo, cán bộ y tế ủng hộ sử dụng sản phẩm.

\section{KẾT LUÂN}

- Cải thiện tình trạng dinh dưỡng: cân nặng: sau 1 tháng $(0,46 \pm 0,13 \mathrm{~kg}$ so với 0,18 
$\pm 0,10 \mathrm{~kg}$ ), chênh lệch $0,28 \mathrm{~kg}$, có YNTK $(p<0,05)$; sau 2 tháng $(0,93 \pm 0,3 \mathrm{~kg}$ so với 0,36 $\pm 0,17 \mathrm{~kg})$ chênh lệch $0,57 \mathrm{~kg}$, có YNTK $(p<0,01)$; chiều cao: chiều cao nhóm can thiệp có mức tăng tốt hơn nhóm chứng $(0,96 \pm 0,10 \mathrm{~cm}$ so với $0,59 \pm 0,17 \mathrm{~cm})$, chênh lệch $0,37 \mathrm{~cm}$, có YNTK $(p<0,05)$. Làm giảm tình trạng SDD và nguy cơ SDD: SDD thể nhẹ cân giảm $12,7 \%$ có YNTK $(p<0,05)$; nguy cơ SDD nhe cân giảm $14,5 \%$ có YNTK $(p<0,05)$. Không xuất hiện thừa cân, béo phì.

- Có xu hướng cải thiện tình trạng nhiễm khuẩn hô hấp, tiêu chảy, táo bón biếng ăn, khó ngủ: tỷ lệ mắc ở nhóm can thiệp thấp hơn so với nhóm chứng: nhiễm khuẩn hô hấp $(7,3 \% ; 9,1 \%)$; tiêu chảy $(6,4 \% ; 9,1 \%)$; táo bón $(4,5 \% ; 7,3 \%)$; biếng ăn $(10,9 \%$; $14,5 \%)$; khó ngủ $(7,3 \% ; 9,1 \%)$ nhưng số liệu còn ít chưa đủ làm kiểm định hoặc không có YNTK ( $p>0,05)$.

- Khả năng chấp nhận sử dụng cao: $96,3 \%$ số trẻ uống đủ khẩu phần sữa (2 bữa/ngày trong 2 tháng). Chương trình bổ sung sữa được gia đình, nhà trường, chính quyền, y tế ủng hộ.

\section{TÀI LIÊU THAM KHẢO}

1. Chính phủ (2015). Chiến lược quốc gia về dinh dưỡng giai đoạn 2011 - 2020 và tầm nhin đến năm 2030.

2. Chính phủ (2016). Chương trình sữa hoc đường cải thiện tình trạng dinh dưỡng góp phần nâng cao tầm vóc trẻ em mẫu giáo và tiểu học đến năm 2020.

3. Best C., Neufingerl N., Del Rosso J.M., et al. (2011). Can multi-micronutrient food fortification improve the micronutrient status, growth, health, and cognition of schoolchildren? a systematic review. Nutr Rev, 69(4), 186-204.

4. World Health Organization (2013). Essential Nutrition Actions: improving maternal, newborn, infant and young child health and nutrition.

5. World Health Organization (2007). The new WHO child growth standards. Bull World Heal Organ, 52(1), 13-17.

6. Flodin N.w. (1997). The metabolic roles pharmacology, and toxicology of lysine. J Am Coll Nutr, 16(1), 7-21.

7. Gombart A.F., Pierre $A_{\text {., }}$ and Maggini S. (2020). A Review of Micronutrients and the Immune System-Working in Harmony to Reduce the Risk of Infection. Nutrients, 12(1), 123-133.

\section{SẢN XUẤT THUỐC BẰNG CÔNG NGHỆ IN 3D FDM PHẦN 2: CẢI THIỆN CHẤT LƯỢNG SẢN PHẨM IN 3D FDM}

Lê Thị Thu Trang*, Trần Thị Hải Yến*, Võ Quốc Ánh*

\section{TÓM TẮT}

Trong những năm gân đây, công nghêe in 3D dựa trên nguyên lý FDM (fused deposition modeling) được nhiều nhà khoa học chú ý bởi những điểm sáng như khả năng ứng dụng rộng rãi và tiết kiệm chi phí. Tuy vậy, cũng giống như các kỹ thuật in 3D khác, chất lượng của sản phẩm FDM luôn là mối quan tâm lo ngai hàng đâu. Bài tổng quan này trình bày hai yếu tố chính, trực tiếp ảnh hưởng tới chất lượng của một vật thể in đó là nguyên vât liệu và thông số in. Bên canh đó, bài viết đề cập tới những nguyên nhân, mức độ ảnh hưởng của một số sư cố thường găp trong quá trình in 3D. Đồng thời, bài viết cũng tônng hợp những kinh nghiêm thành công khắc phuc sự cố kỹ thuât từ những nghiên cứu gân đây, tất cả cho một mục đích nâng cao chất lượng thuốc.

Từ khóa: Công nghệ in 3D, thuốc in 3D, cá nhân hóa điều trị, khắc phục sự cố trong in 3D.

\section{SUMMARY}

*Trường đại hoc Dước Hà Nôi

Chịu trách nhiệm chính: Võ Quốc Ánh

Email: anhvq@hup.edu.vn

Ngày nhận bài: 12.4.2021

Ngày phản biên khoa họ: 26.5.2021

Ngày duyệt bài: 14.6.2021

\section{QUALITY IMPROVEMENTS ON THE} PHARMACEUTICAL APPLICATION OF FUSED DEPOSITION MODELING 3D PRITING

Fused deposition modeling is a type of additive manufacturing technology that allows the production of three-dimensional (3D) devices from a computeraided design (CAD) file. FDM is an user-friendly, lowcost technique to quickly print prototypes with complex geometry. However, the FDM technique has some limitations due to its use of high temperatures. These temperatures may lead to potential thermal degradation, shrinkage issues, low surface quality and poor resolution. Moreover, although FDM is a fairly well-known 3DP technique, it is still a complex process to control. This complexity is due to the relatively high number of parameters that may affect the quality of final printed products. This paper aims to inform about 2 major factors that directly affect the quality of 3D printed products. Additionally, frequently encountered technical issues and approaches to solving the problems, improving product quality were also discussed.

Keywords: Three-dimension (3D) printing, 3D printed drugs, fused deposition modeling, material extrusion.

Từ ngữ viêt tăt: GPKD: Giải phóng kéo dài; $\mathrm{PCL}$ : polycaprolactone; HPMC: Hydroxypropyl Methylcellulose; HPC: hydroxypropyl cellulose; PEO: Polyethylene oxide; PEG: Polyethylene glycol; Kollidon ${ }^{\circledR}$ VA64: polyvinyl pyrrolidone vinyl acetate 64; 